\section{You Should Publish That! A Primer On Educational Publishing}

$\mathrm{H}$ ave you ever used a textbook with your class and thought, "I could write something more interesting than this?" Perhaps you have developed a set of activities to support a strand of the curriculum and your colleagues say, "You should get that published!" Or you may have written a practical guide as part of an additional qualification or graduate course and realized it would be useful to other teachers.

Many educators can answer yes to at least one of these scenarios, but most never take the necessary steps to connect with a publisher. Would-be authors often assume that publishers have hundreds of writers vying for their attention or that no educational publisher is interested in talking with an unpublished writer. The reality is that publishers are always on the lookout for new talent to develop, and welcome teachers who have fresh approaches to classroom practice.

In this paper, I outline a series of steps potential writers can follow to connect with educational publishers. I then look more closely at the process of producing a product once a contract has been signed with a publishing company.

\section{Getting Started}

You have knowledge and skills that are marketable. Approach the prospect of writing as an entrepreneur would. See your writing career not as a one-time undertaking but rather as a business that you are willing to build over time.

\section{Ruth McQuirter Scott}

The following steps will help you to present yourself in the best light to a prospective publisher.

1. Assess what you can offer a publisher. Begin by listing all the writing you have done in the last five years. Highlight these endeavours in your resume. You may think you have little to record, but consider the following:

- Unit plans you have produced either alone or as part of a team

- Contributions to curriculum writing teams at the school or district level

- Storybooks you have created for your classroom

- Projects done as part of pre-service, additional qualifications, or graduate courses

- Innovative approaches you have developed in areas such as assessment and evaluation, program modification for special needs children, English as a Second Language classes, connecting with parents

- Book reviews written for journals or newspapers

- Committees you have served on that have investigated special issues such as bullying, gifted education, literacy and numeracy

- Workshops you have developed and delivered to colleagues as part of a staff presentation or at outside conferences

Don't be concerned about whether these products are ready for mass publication. Most likely a publisher would view them simply as evidence of your writing style, your knowledge of curricu- lum, and your ability to express yourself clearly.

If you have little written material to offer a publisher at this point, determine to become involved in writing projects at the school and board levels. With new initiatives being introduced regularly by the Ministry of Education, there are many opportunities for teachers to contribute their front-line knowledge. It is also an excellent way to make contacts with consultants and coordinators who may link you with other colleagues who have similar interests.

2. Brainstorm the "hot issues" in education. Make a list of topics or subject areas that seem to be on everyone's agenda. Ask yourself these questions:

- What educational topics seem to be reported most often in the press?

- What workshop offerings have been popular in recent professional development experiences?

- How might you and your colleagues complete this statement: "If I could only find a resource for teaching , my job would be so much easier."

- Read recently published ministry documents, looking for current "buzz words." What do these terms mean at the classroom level? What have you already done or are planning to do that would put a practical spin on this educational jargon?

3. Analyze what is currently available from publishers. Ask your teacher librarian or call companies for your own copy of a wide assortment of publishers' catalogues. Examine these resources closely and conduct a "gap analysis." Which "hot topics" brainstormed above have publishing companies failed to address? Make a list of these areas of need. 
4. Observe the types of resources produced by each company. Some publishers specialize in textbooks for students, while others focus on professional development books for teachers and administrators. Still others produce consumable materials based on specific topics linked with provincial curriculum documents. It is important to know which publishers to approach for the type of writing you wish to do.

5. Prepare a list of topics or subject areas you would be interested in writing about. This list should be based on your areas of strength, your personal interests, and the needs you see in the field. It is always important to keep in mind the end-user of what you might write. Publishing is a business, and companies will only invest in a project if they think there is a market willing to purchase the product.

6. Update your resume to emphasize your potential as a writer. Include the experiences you listed above as well as any other involvements that show your professional commitments and connections. Publishers may be impressed, for example, that you have been selected to mentor new teachers on staff or to supervise pre-service candidates in their teaching blocks. They may also appreciate that you have taught at a variety of grade levels or in different educational settings.

\section{Approaching a Publisher}

There are many ways to initiate contact with a publishing company, and it is often a good idea to make some inquiry calls. Look on the company's website to determine the person in charge of the subject area you are interested in. Some companies welcome phone calls or e-mails that are then followed up with an introductory package from the prospective writer. The publisher will read it both for its content and for evidence of your writing ability. If the letter is too wordy or contains errors in spelling or grammar, your credibility as a writer will suffer.

It often helps to talk with a sales representative of the company during book displays or to call this person directly. Many companies rely on their representatives to scout educators who seem knowledgeable and current about issues in education. They will also look for a match between your approach to teaching a specific subject such as mathematics or language arts and that of the publishing company. The representative will likely be able to tell you whether the company is currently developing materials in your areas of interest.

\section{Preparing a Proposal}

If you have a specific idea for a book or resource you would like to write, your job is to convince the publisher that this is a viable project. You will need to state clearly and concisely how your book will fill a need in the educational market. Publishers vary in how detailed they wish proposals to be, but most proposals answer the following basic questions:

-What will this book be about?

-What is the target audience?

- How will the book be organized? (A sample table of contents is a good idea)

- What other books have been written about this topic? How will yours fill a gap?

- What background do you have on this topic? What research or field experience have you engaged in?

- How much have you already written? (A sample chapter is often recommended)
A thorough discussion of proposals as well as a sample proposal can be found on the website for Stenhouse Publishers (www.stenhouse.com). While some publishers expect the detailed proposals described on this website, others prefer a simpler approach. One publisher may ask for a query letter that describes the idea and topic. You should be able to state in two or three sentences what your book will add to the educational market in a voice that addresses the teacher need. Another publisher may prefer a sample of your writing in addition to the covering letter. If you have worked, for example, on a board project, include the pages you contributed. Contact the publisher ahead of time or look on its website to determine the most suitable way of approaching the company. Regardless of the format, your goal is to convince the publisher that your proposal is worthy of a second look.

It is considered proper etiquette to approach one publisher at a time with a proposal. After a few weeks, follow up with a phone call. Do not be discouraged if your proposal is rejected. It may be that your topic simply doesn't fit into the company's publishing plans for the coming year. Many publishers will give helpful advice for improving your proposal or suggest another company that publishes the type of resource you have described. Many successful books have been rejected by several companies before being accepted for publication. If you believe in your idea, persevere until you connect with the right publisher.

\section{They're interested in me! Now what?}

In some cases, a publisher will be so impressed by a proposal that the project is approved as is. More likely, however, they will want to 
see you in action before making a major commitment to you as an author. You may be invited to work on a portion of a larger project, such as contributing to a teacher's guide, or to write student activities for a student anthology. Your input could be requested in focus groups or as a reviewer for manuscripts already underway.

In each instance, the publisher will be observing your performance in a number of areas. Can you be relied upon to meet deadlines? Are you open to editing suggestions and able to revise your work according to the editor's instructions? Do you work well on a team or do you insist on having things your way? Is your writing clear, concise, and engaging? Are you able to translate educational theory into practice so that it comes alive to teachers? Can you adjust your writing voice to the intended audience?

\section{Do I do this by myself?}

Each writing project is assigned an editor whose job it is to work with writers. The editor assigns deadlines, receives your drafts, and responds to them. There is usually a close working relationship between the editor and authors. It isn't easy to receive feedback on a piece of writing and to have it covered in editorial suggestions. Experienced writers, however, learn to value good editors because they bring to the manuscript an objectivity that is hard for writers to achieve.

\section{What about contracts?}

If you are hired by a publisher to work on a project, you will receive a legal contract. Your payment will either be a specified fee for the work or a royalty rate based on sales of the product. Most writers begin with a set fee and are only offered royalties if they are the major author of a work. Even in this instance, the company may choose to offer a specified fee rather than royalties. There are advantages and drawbacks to both arrangements. On the one hand, with a set fee the writer knows exactly how much income will be generated by the work and it is paid soon after the manuscript is completed. Royalties are based on sales, so actual payments may not begin for several months. On the other hand, a popular book or program can remain in print for several years, and earn the writer many times what a set fee would have paid.

It is wise to read your contract carefully and seek the advice of a lawyer if you have questions. Asking for clarification ahead of time is far easier than trying to renegotiate once the work is in progress.

\section{How much money am I likely to make?}

Some experienced authors make a sizable income from their educational writing. This is not, however, the typical scenario. If, for example, a book sells for $\$ 30$, and the author makes a royalty of $8 \%$, the initial payment is $\$ 2.40$. This sum is further reduced by income taxes in accordance with the writer's income level. At the same time, the writer has to pay for all personal costs associated with producing the work, such as paper, computer, postage, and so forth.

For many writers, however, the relatively low income generated by the work itself is compensated for in other ways. If you can show a steady income from writing over a period of time, you are considered to have a small business, and can claim many deductions related to the office space in your house and other costs of running your business. An accountant can advise you in this area.
Once you have authored a work you can join Access Copyright, an agency that works on behalf of publishers and creators to collect fees from institutions for photocopying works. You will receive a payment each year based on an estimate of the number of pages of your work that have been copied. Furthermore, each member of Access receives a lump sum payment annually for fees that cannot be distributed otherwise. In 2004, each member received just over $\$ 500$.

\section{Is it worth it?}

You must decide whether the discipline required to be a writer of educational materials fits your personal style and goals. Although it takes time and perseverance to be successful in this field, seeing your work in print can be a tremendously satisfying experience. It is also a way of making a lasting contribution to the teaching profession. Educational research seldom has a significant impact on the classroom as long as it remains in scholarly journals. Real change can occur, however, when creative, informed writers translate new concepts into resources that teachers and students can understand and enjoy.

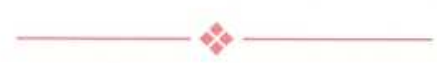

Ruth McQuirter Scott is an Associate Professor in the Faculty of Education at Brock University.

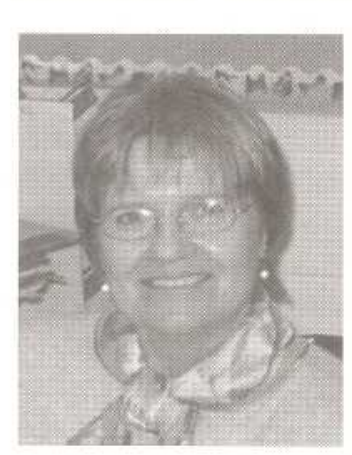
She has authored or co-authored over thirty books in the field of spelling, and conducts workshops on educational publishing. 